This is the final peer-reviewed accepted manuscript of:

Mameli, C., Molinari, L. Teaching interactive practices and burnout: a study on Italian teachers. Eur J Psychol Educ 32, 219-234 (2017)

The final published version is available online at:

https://doi.org/10.1007/s10212-016-0291-z

Rights / License:

The terms and conditions for the reuse of this version of the manuscript are specified in the publishing policy. For all terms of use and more information see the publisher's website. 


\title{
Teaching interactive practices and burnout: a study on Italian teachers
}

\author{
Consuelo Mameli ${ }^{1} \&$ Luisa Molinari ${ }^{2}$
}

\begin{abstract}
The purpose of the present study was to analyse the role played by teaching interactive practices (measured through a self-report Likert scale) in predicting teacher burn-out, after controlling for school grade (primary vs. secondary school) and teaching experience. Participants were 282 Italian teachers equally distributed between primary and secondary schools. Teaching interactive practices were investigated through a purposebuilt questionnaire concerning teacher- versus student-centred practices. Burnout was studied using the Maslach Burnout Inventory in its three-dimensional-Emotional Exhaustion, Low Personal Accom-plishment and Depersonalization-Italian version. An explorative factor analysis on the questionnaire displayed three dimensions of teaching practices, namely student-centred prac-tices focused on flexibility, student-centred practices focused on participation and teacher-centred practices. The main results showed that, irrespective of school grade and teaching experience, the adoption of interactive practices favouring students' participation negatively predicted burnout; on the contrary, teacher-centred practices and flexibility positively predicted it. The result implications for educational processes and teacher training are discussed in the conclusion.
\end{abstract}

Keywords Teaching interactive practices $\cdot$ Teacher burnout - Student participation - Teachercentred practices $\cdot$ Student-centred practices

* Consuelo Mameli

consuelo.mameli@unibo.it

Luisa Molinari

luisa.molinari@unipr.it

1 Department of Education, University of Bologna, Via Filippo Re 6, 40126 Bologna, Italy

2 Department of Literature Arts History and Society, University of Parma, Borgo Carissimi 10, 40125 Parma, Italy 


\section{Introduction}

Over the last few decades in Italy, like in other countries, schools have undergone a series of changes due, on the one hand, to profound demographic and social transformations, including the increasing rate of foreign students (Italian Ministry of Education 2013) and, on the other, to the implementation of educational reforms. As Zurlo et al. (2007) have pointed out, Italian teachers experience feelings of overload mainly depending on three school reform aspects: first, the increase in teachers' responsibilities vis-à-vis the local school governance; second, changes in the curriculum and third, implementation of a teacher assessment model. These renovations have deeply affected teachers' lives and work, as they have been asked to implement the novelties introduced by the reforms while also taking into account the demanding challenges coming from society. One of the consequences is that many teachers perceive a generalized sense of bearing a weight and they report feelings of exhaustion and professional dissatisfaction (Gold and Roth 2013; Guglielmi et al. 2012; Khan et al. 2014; Schaufeli et al. 2009).

Based on these considerations, the variety of situations that teachers encounter today in their everyday life brings with it the need for them to be equipped with skills that go well beyond their competence in conveying knowledge. In classrooms, they are called upon to adopt and govern a number of actions, such as building up meaningful educational relationships with students, including those with special needs, or managing large, heterogeneous and often problematic class groups (Ferguson 2008; Hastings and Bham 2003; Hughes et al. 2008; Jennings and Greenberg 2009). The perceived pressure stemming from handling these com-plex tasks is associated with negative feelings (Ballet and Kelchtermans 2009; Greenglass and Burke 2003; Veldman et al. 2013) that the literature consistently describes as teacher burnout (Aloe et al. 2014; Aydogan et al. 2009; Chan 2006; Skaalvik and Skaalvik 2009).

Beyond the structural and organizational aspects, there is yet another factor that we assume may affect feelings of teachers' professional realization or burnout. It regards teaching practices that teachers adopt for guiding the lesson in their everyday work, and especially teachers' orientation to favour or limit the interactions with their students. Student participation in classroom lessons is indeed considered as a value in the most prominent approaches on educational quality, according to which "one of the principal tasks of the teachers is to create interactive opportunities and encounters" (Alexander 2008, p. 92). We argue then that the perception of being able to promote students' engagement and participation may be associated with feelings of professional fulfilment that prevent from burnout.

\section{Teaching interactive practices}

Many authors have conducted empirical research on teaching interactive practices in primary (Alexander 2001; Mercer and Littleton 2007; Niemi et al. 2015; Wegerif et al. 1999) and secondary classrooms (Aguiar et al. 2010; Allen et al. 2013; Scott et al. 2006). However, a clear definition of the construct is still lacking. Teaching practices are described by Ball and Forzani (2009) in general terms as "the work of teaching [...] such as leading a discussion of solutions to a mathematics problem, probing students' answers, reviewing material for a science test, [...] planning, and creating and maintaining an orderly and supportive environment for learning" ( $\mathrm{p}$. 497). Other authors have offered definitions that focus more closely on the interactive side of teaching. Kloser (2014), for instance, argues that teaching practices comprise the instructional repertoire (e.g., strategies or procedures) that impacts on students' behaviour and engagement. 
Spillane (2012) goes further in defining teaching practices as the "more or less coordinated, patterned and meaningful interactions of people at work" (p. 114). In line with these definitions, in the current paper we refer to teaching interactive practices as the actions that teachers enact in order to foster or limit students' participation and engagement in classroom activities (Alexander 2008; Buty and Mortimer 2008; Lyle 2008; Mercer and Howe 2012; Yüksel 2009).

In this field, the literature has traditionally distinguished two kinds of interactive practices (Baeten et al. 2010; Brocato 2009; Freiberg and Lamb 2009; Garrett 2008), broadly corre-sponding to the two poles of a continuum ranging from completely teacher-centred to completely student-centred teaching practices (Kember 1998).

In teacher-centred practices, the teacher's role is overall to transmit knowledge and contents, and the students' role is to be receptive and able to master such contents. Through such practices, the adult decides what counts or does not count as knowledge and determines the lesson content and organization. In classroom talk, teachers make use of the so-called monologic discourse (Alexander 2001; Lefstein 2008; Lefstein and Snell 2011; Lyle 2008), focused on curricular implementation and the maintenance of control over classroom activities. With this kind of practices, teachers maintain the power of being the only legitimated primary knower, and students are called to respect the direction that the adult has foreseen with the use of focused questions having a single right answer (Lin 2007; Mascolo 2009).

On the contrary, student-centred practices express the teacher's attitude to consider students as active participants in the lessons. As such, they reflect the socio-cultural view that considers learning as taking place via interaction more than in individual minds and knowledge as co-constructed through the network of interactions (Lipponen and Kumpulainen 2011; Mameli et al. 2015). When adopting these practices, teachers do not function as the primary source of knowledge in the classroom. On the contrary, they act as facilitators assisting students who "are seen as the primary architects of their learning" (Mascolo 2009, p. 4) and sustain dialogue as "pivotal to student learning and understanding across all ages and topics because it underpins the process of learning to think" (Higham et al. 2014, p. 87). Among the many practices that can be considered as student-centred, the most studied are those facilitating students' participation in classroom lessons, such as those promoting discussions and triadic or multiple interactions (Alexander 2006; Mameli and Molinari 2014; Wegerif 2008).

Other student-centred actions are based on the teachers' attitude to be flexible in responding to the classroom needs or requests and in addressing the multiple knowledge opportunities that emerge moment by moment in everyday lessons (Kovalainen and Kumpulainen 2007; Scott et al. 2006; Skidmore and Murakami 2010). With these practices, teachers enact "a flexible repertoire of highleverage strategies and techniques that can be deployed with good judgment depending on the specific situation and context" (Ball and Forzani 2009, p. 503). In the classroom, the possibility to adapt to the discursive and interactive flow depends on the teacher's ability to avoid an inflexible adherence to pre-planned activities and to adapt to the learning needs and requests arising turn after turn (Molinari and Mameli 2013). By following the discourse trend, teachers and students thus go through a series of readjustments, regarding the aims of the lesson and the nature of their interactions, offering them chances to fully exploit the power of the discursive interactions.

Over the last decade, a number of studies, mainly based on observational methods, have provided evidence that high-quality teaching (Lyle 2008; Mortimer and Scott 2003; Nassaji and Wells 2000; Scott et al. 2006; Wells and Arauz 2006) is represented by student-centred interactive practices, able to facilitate students' participation and to respond flexibly to the learners' needs and emerging situations (Candela 2005; Kovalainen and Kumpulainen 2007; Molinari and Mameli 2013; Wells and Arauz 2006). Most research in this field has been 
carried out in primary schools, whose teachers are generally portrayed as having greater flexibility and being more student-oriented as compared with secondary school teachers. According to Higham et al. (2014), a reason for this primary bias is located in the fact that primary school teachers spend more time with the pupils in the classroom, have more freedom in the curriculum and are less engaged in evaluation and grading tasks. However, a more systematic analysis of school grade as a factor influencing teaching practices is still needed.

\section{Teacher burnout}

Burnout is typically defined as a response to chronic stress related to helping professions. Most studies on burnout make use of the Maslach Burnout Inventory (MBI-Maslach and Jackson 1981; Maslach et al. 1996a) for its measurement. This questionnaire is made up of three scales: emotional exhaustion, low personal accomplishment and depersonalization. Emotional exhaustion refers to feelings of frustration that are accompanied by low levels of energy and tension. Low personal accomplishment regards the sense of ineffectiveness related to work and a lack of confidence in one's own abilities. Depersonalization indicates the need to take a distance from an "other", who is thus treated in a dehumanizing way as if s/he was an object. This questionnaire has been used in a vast number of studies performed on different populations (Aguayo et al. 2011; Schaufeli et al. 2009). However, some authors (for a review, see Worley et al. 2008) have expressed concerns about the depersonalization scale for its relatively low internal consistency.

As regards the measurement of teachers' burnout in particular, a more recent version of the Inventory (Educators Survey-MBI-ES; Maslach et al. 1996b) has been specifically developed. Overall, the results of the research performed with this instrument converge in identifying teaching as an especially stressful profession (Chaplain 2008; Montgomery and Rupp 2005). This is mainly considered as being due to an interaction of personal characteristics, together with subjective and environmental variables. Among the former, personality plays a major role. Various studies have shown that low extraversion and high neuroticism were positively associated with high levels of teacher burnout (Cano-Garcia et al. 2005; Kokkinos 2007; Maslach et al. 2001). The subjective dimensions of teaching have been confirmed as important in an Italian study performed on a large sample of teachers (Guglielmi et al. 2012), showing that the personal mental fatigue in fulfilling the tasks demanded on teachers had a major impact on stress and burnout. The environmental impact was studied with reference, in particular, to low administrative and colleague support (Grayson and Alvarez 2008), time pressure and poor working conditions (Tsouloupas et al. 2010) and large class sizes (Klassen and Chiu 2010; Travers and Cooper 1996).

Moreover, the school type and the teaching experience also play a role in the burnout onset. Research performed in Italy (Quattrin et al. 2009; Pedditzi and Nonnis 2014) as well as in other countries (Betoret and Artiga 2010) has shown that secondary school teachers had higher levels of emotional exhaustion and feelings of depersonalization (Vercambre et al. 2009) as compared with primary school teachers, while the opposite was found in other studies (Kokkinos 2006; Tatar and Horenczyk 2003; Tsigilis et al. 2011). Also the results of research assessing the role of teaching experience were rather contradictory. In some of the studies, teachers in the early years of their career resulted to be more vulnerable to low feelings of job satisfaction (Boles et al. 2000; Maslach and Jackson 1981; Taylor and Tashakkori 1995), were less integrated in the workplace and felt less satisfied (Gavish and Friedman 2010). Other studies instead showed that highly experienced teachers were more susceptible to burnout and less professionally satisfied (Kokkinos 2007; Xin and MacMillan 1999), while other findings did not indicate significant differences in burnout levels depending on the years of experience (Bataineh 2009). 
The influence of teachers' everyday classroom work on burnout has received much less attention. Some studies have shown that students' misbehaviour and management difficulties (Aloe et al. 2014; McCormick and Barnett 2011) are stress-inducing. However, as far as we know, the impact that teaching interactive practices exert on burnout is an issue that still needs to be addressed in the literature.

\section{Research aim}

From the literature review, there are several issues that still deserve further investigation. Firstly, previous research has identified student-centred teaching practices, fostering participa-tion and denoting flexibility, as those that better correspond to educational quality (Ball and Forzani 2009; Lefstein and Snell 2011; Lipponen and Kumpulainen 2011; Mascolo 2009; Mercer and Howe 2012). However, such research is mostly based on observational studies, while a self-report scale on teaching interactive practices has not been developed so far. Secondly, it was assumed that primary teachers are more prone to make use of such practices but research has not provided clear evidence in this respect. A study based on the comparison between primary and secondary school teachers may contribute to advance knowledge in the field. Finally, while much is known about personal and environmental variables affecting professional stress and exhaustion, the role of teaching interactive practices on teacher burnout still needs to be explored.

The current study intends to fill in these literature gaps by analysing the role played by teaching interactive practices (measured through a self-report Likert scale) in predicting teacher burnout, after controlling for type of school and teaching experience.

The study procedure was twofold. We first explored teaching interactive practices with a purpose built questionnaire, based on items reflecting teacher- and student-centred interactive practices. The decision to build a dedicated questionnaire was dictated by the fact that there is a tendency in the literature to examine the theoretical or abstract conceptions of teaching rather than how teachers essentially perceive what they actually do in their everyday classroom work (Eley 2006; Kane et al. 2002).

We then analysed the role played by teaching interactive practices on burnout. Based on the conclusions of studies that valorise teacher-student interactions in terms of educational quality (Aguiar et al. 2010; Burns and Myhill 2004; Lefstein 2008; Lin 2007; Mercer 2008; Molinari and Mameli 2013; Nystrand 1997; Wells and Arauz 2006) we predict that, irrespective of the type of school where they teach and the length of their teaching experience, teachers who report to adopt high-quality interactive practices will experience lower levels of burnout. On the contrary, the adoption of teacher-centred practices, which limit and control interaction and students' participation, might negatively affect feelings of professional fulfilment.

\section{Methodology}

\section{Participants}

We distributed a questionnaire to a population consisting of 282 Italian teachers, mostly females $(88.4 \%)$, coming from several schools located in a medium-sized town. They were equally divided into primary $(n=141$; students age from 6 to 11 years old) and secondary school ( $n=141$; students age from 11 to 19 years old) teachers. Their teaching experience 
varied from 1 to 40 years $(M=20.33, S D=9.38)$. As for the subjects they taught, $43.0 \%$ of the teachers taught humanities, $37.2 \%$ mathematics and science and the remaining $19.8 \%$ taught other subjects, such as religion or economics.

\section{Procedure}

We first presented the study to the school principals and teacher representatives. After receiving approval from the schools, we invited all the teachers to fill in an online question-naire, via a specific URL link that was created specifically for this purpose. In all the participating schools, a print version of the questionnaire (including a preaddressed envelope that teachers could use after filling it in) was also made available to individuals who were uncomfortable with electronic procedures. This print version was preferred by $11 \%(n=31)$ of the participants.

Both the electronic and the printed questionnaires were accompanied by an introduction that outlined the general aim of the study and emphasized data confidentiality and anonymity.

\section{Measures}

Teaching practices. The first scale of the questionnaire focused on the practices that teachers perceive they adopted to guide the lesson and to interact with their students during classroom activities. The $17-$ item $^{1}$ scale was created specifically for this study. More specifically, the items covered the two interactive practices described above: (a) teachercentred (the teacher models the lesson goals and provides direct right/wrong feedback); (b) student-centred (students are encouraged to actively participate in the lesson and the teacher shows flexibility in responding to learners' requests). Teachers were asked to answer each item on a scale ranging from 1 ("It never happens during my lessons") to 5 ("It always happens during my lessons").

Teacher burnout. This issue was assessed using the MBI (Maslach and Jackson 1981) in its validated Italian version (Sirigatti and Stefanile 1992) with specific reference to teaching staff. The MBI consists of 22 items grouped into three scales: emotional exhaustion (nine items, e.g. "I feel emotionally drained by my work"), low personal accomplishment (eight items, e.g. "I can easily create a relaxed atmosphere with my students" ) and depersonalization (five items,

e.g. "I feel students blame me for some of their problems"). Teachers were asked to indicate how frequently they experienced these feelings on a 7-point scale, ranging from 0 ("Never") to 6 ("Daily"). For the current study, Cronbach's alphas were .83 for emotional exhaustion, .78 for low personal accomplishment and .51 for depersonalization. Due to the low internal consistency, we eliminated from further analyses the depersonalization scale, elsewhere already criticised for the low validity of the construct (Lee and Ashforth 1996; Worley et al. 2008). Means (M) and standard deviations (SD) were the following: emotional exhaustion $\mathrm{M}=2.01, \mathrm{SD}=1.04$; low personal accomplishment $\mathrm{M}=1.63, \mathrm{SD}=.70$.

\footnotetext{
${ }^{1}$ At first, the scale comprised 35 items. However, after a series of analyses carried out in a pilot study, we excluded the items showing low loadings and communalities.

${ }^{2}$ The personal accomplishment scale of the MBI included only positively worded items, which were subsequently reversed in order to evaluate a low sense of personal accomplishment (Simbula and Guglielmi 2010).
} 


\section{Results}

\section{Teaching interactive practices}

Preliminary analyses carried out on the 17 items composing the scale revealed that means had a range of 1.95 to 4.58 (on the 5-point scale) and standard deviations were between .57 and 1.15. Item skewness varied from -.965 ("I make efforts to encourage equal participation by all my students") to .722 ("I plan and organize my lesson in advance"). Kurtosis ranged from -.913 ("I feel that my class is listless and uninterested") to .661 ("After a wrong answer, I reformulate the questions with more information").

The data was considered suitable for factor analysis following the multiple "rule of thumbs" that included the Kaiser-Meyer-Olkin (KMO) measure of sampling adequacy (0.750) and Bartlett's test of sphericity $\left(\chi^{2}=788.127, d f=136, p<.001\right)$. First, a principal component factor analysis without rotation was carried out on all the items. The decision to use an exploratory factor analysis was based on the fact that the factor structure of teachers' interactive practices was unknown. An inspection of the factor screen plot was conducted to determine the best number of factors to be retained. The analyses returned three reliable factors with acceptable eigenvalues (ranging from 3.33 to 1.85 ). After that, a principal component factor analysis with an oblique rotation (Oblimin criterion) confirmed the presence of three components accounting for $43.75 \%$ of the total variance. Oblimin rotation was appropriate in this study because we assume that the factors can be correlated.

The factor matrix is presented in Table 1. The factors were labelled as follows: student-centred practices focused on flexibility (SC Flexibility), student-centred practices focused on participation (SC Participation) and teacher-centred practices (TC). Two of the items composing the first factor were reversed (they are identified in Table 1 with an "R" reported after the statement).

The factor on SC Flexibility was centred on the idea that whatever plans a teacher can have, they might always change depending on the classroom response. The factor on SC Participation comprised items expressing the practice to encourage participation and to treat all the students, whatever their level of performance, in an equal manner. The factor on TC practices depicted a vision of the lesson as following a pre-organized plan, with a low level of students' involvement and based on a strict boundary between what is "right" and what is "wrong".

Table 2 reports the descriptive statistics, internal consistencies (Cronbach's alpha) and correlations among the three factors. The mean value of SC Participation was quite high if compared with the other factors, and this confirmed the high value teachers attribute to the promotion of students' active role during the lessons. The correlations were moderate in magnitude, indicating that the dimensions were distinct although not totally independent. The negative relations between TC and both SC practices confirmed they correspond to opposite ways to conduct and perceive classroom activities.

\section{The relationship between teaching practices and burnout}

Two separate hierarchical linear regression analyses were conducted to estimate the effects of teaching interactive practices on each of the two burnout dimensions, i.e. emotional exhaustion and low personal accomplishment. We controlled the effect of school grade and teaching 
Student-centred practices: Flexibility

The interactive flow of my lessons is unpredictable

$.732-.053 \quad .045$

During a lesson, it can happen that I change my plans

$.719 \quad-.123 \quad .106$

I plan and organize my lesson in advance (R)

$.667 \quad-.055 \quad .115$

I feel I am guided by my students during the lesson

$\begin{array}{lll}.638 & .274 \quad .290\end{array}$

It is important for me to keep full control of my lesson (R)

$\begin{array}{lll}.593 \quad .389 & .203 \quad .39\end{array}$

I foster dialogues among students

$.508 \quad-.207 \quad .047$

Student-centred practices: Participation

Even the low-performing students are asked to participate in my lessons

$\begin{array}{lll}.105 & -.772 \quad .195\end{array}$

I make efforts to encourage equal participation by all my students

$.016 \quad-.693 \quad .212$

I get my students involved and engaged during my lessons

$.013 \quad-.671 \quad .041$

After a wrong answer, I reformulate the questions with more information

$.112-.584-.091$

Teacher-centred practices

I feel that my class is listless and uninterested

$.050 \quad .276 \quad-.665$

During my lesson, contributions come from a few and always the same students $\quad \begin{array}{rrrr}\text {-.071 } & .224 & -.640\end{array}$

If a student's contribution is off-topic, I think that $\mathrm{s} /$ he was not paying attention $\quad-.196 \quad-.123 \quad-.611$

If a student's answer is wrong, I ask another one to provide an answer $\quad-.235 \quad \begin{array}{lll}.130 & -.565\end{array}$

When a student is wrong, I provide suggestions for the right answer $\quad-.192-\begin{array}{lll}-.103 & -.558\end{array}$

I formulate questions for which there is only one right answer

$-.252-.045-.524$

When I finish a lesson, I feel I did not finish what I had planned to do

$.140 \quad .052 \quad-.457$

Percentages of variance explained

$10.89 \quad 13.29$

Principal axis factor analysis with oblimin rotation

experience by entering them as dichotomic variables ${ }^{3}$ in step one of the regressions. The three scales of teaching interactive practices were entered in the second step of each analysis.

Before proceeding with the analysis, the data were examined for outliers and for conformity with a normal distribution. Using boxplots, we identified three outliers in the teaching interactive practice subscales (one for SC Flexibility and two for TC). We also identified two outliers in the burnout dimensions, one for emotional exhaustion and one for low personal accomplishment. All these cases were eliminated from the data, reducing the sample size from 282 to 277 participants. For all the variables included in our regression models, values for skewness (range from -.507 to .644) and kurtosis (range from -.374 to .224) were lower than |1|, which suggests that the distribution of the variables was adequate for the analyses. In order to reveal potentially collinearity problems among the predictors, a series of variance inflation factor (VIF) was computed (one for each of the two regressions). As the values of VIF (range from 1.071 to 1.243 ) were lower than the conventional threshold (10), it was concluded that no multicollinearity problems existed.

The results of the two hierarchical regression analyses are presented in Table 3.

In the first set of analyses, related to emotional exhaustion, neither school grade nor teaching experience inserted in step one were significant predictors of the variance. Among

\footnotetext{
${ }^{3}$ In order to dichotomise the variable teaching experience, we chose the median value of the years of teaching, which corresponded to 8 . We then assigned the value 0 to teachers with 1 to 8 years of experience (50.4\%), and the value 1 to the other teachers.
} 
Table 2 Summary statistics and inter-correlations among the teaching interactive practices

\begin{tabular}{|c|c|c|c|c|c|c|}
\hline & $M$ & $S D$ & Internal consistency $(\alpha)$ & \multicolumn{3}{|c|}{ Correlations } \\
\hline & & & & 1 & 2 & 3 \\
\hline 1. SC Flexibility (1-5) & 2.72 & .64 & .73 & - & & \\
\hline 2. SC Participation (1-5) & 4.24 & .50 & .65 & .06 & - & \\
\hline 3. TC (1-5) & 2.71 & .59 & .67 & $-.22 * *$ & $-.14 *$ & - \\
\hline
\end{tabular}

$* p<.05 ; * * p<.01$

the teaching interactive practices added in step two, SC Participation $(\beta=-.16, p<.05)$ and TC $(\beta=.16, p<.05)$ were relevant predictors of emotional exhaustion. Overall, the variables accounted for $8 \%$ of the variance (adjusted $R^{2}=.079$ ).

As regards the second set of analyses, pertaining to low personal accomplishment, no significant predictor was singled out in step one. In step two, SC Flexibility $(\beta=.15, p<.05)$ and SC Participation $(\beta=-.43, p<.001)$ were found as significant predictors of the dependent variable. A total of $19 \%$ of the variance (adjusted $R^{2}=.189$ ) was accounted for the predictor variables.

\section{Discussion}

Teaching interactive practices and their role in predicting teacher burnout were investigated in the present study. We first explored teachers' self-reported practices of teacher-student interactions. The scale we developed revealed satisfying values of internal consistency. Although we should not undervalue a possible effect of social desirability due to the limits of a specifically built questionnaire, and more generally of self-report research, our results offer material for confirming that $\mathrm{TC}$ and $\mathrm{SC}$ interactive practices correspond to opposite ways to guide the lesson and the classroom activities. Moreover, it should be noted that while TC practices were clustered in a single dimension, SC practices were split in two factors, namely flexibility and participation.

More in detail, SC Flexibility described teaching practices that are not pre-planned, as they respond to the needs and demands emerging from the classroom. These practices, which facilitate the birth of open discussions, are fostered by the teacher's ability to temporarily withdraw from control of the activities by accepting the students' ideas and contributions. In this way, teachers sustain a particular "kind of relationship between teacher and students, in which students (...) are treated as active epistemic agents, i.e. participants in the production of their own knowledge" (Skidmore 2006, pp. 505-506).

SC Participation described the student's involvement in classroom discourse, which is open to contributions from all pupils, irrespective of their learning skills and performance. Students' participation is thus conceived as part of the scaffolding process that teachers use when they want to support students who are not comfortable with the task. The idea underlying this dimension is that all students are equal and deserve to receive the same opportunities to be considered as legitimate co-authors of discursive interactions (Candela 2005).

The factor on TC practices closely resembled the dimension reported in the literature and typically described as monologism. Control is at the core of this view, based on the idea that teachers exert their power by limiting students' interventions and directing them towards 
Table 3 Hierarchical regression analyses summary for school grade, teaching experience, SC Flexibility, SC Participation and TC predicting emotional exhaustion and low personal accomplishment

\begin{tabular}{|c|c|c|c|c|}
\hline & \multicolumn{4}{|c|}{ Dependent Variables } \\
\hline & Set 1 & & Set 2 & \\
\hline \multirow[t]{2}{*}{ Step/predictors } & \multicolumn{2}{|c|}{ Emotional exhaustion } & \multicolumn{2}{|c|}{ Low personal accomplishment } \\
\hline & Step 1 & Step 2 & Step 1 & Step 2 \\
\hline School grade & .08 & .02 & .10 & .08 \\
\hline Teacher experience & .12 & .13 & .03 & .08 \\
\hline SC Flexibility & & .03 & & $.15^{*}$ \\
\hline SC Participation & & $-.16^{*}$ & & $-.43 * * *$ \\
\hline $\mathrm{TC}$ & & $.16^{*}$ & & .05 \\
\hline$F$ & 1.75 & $2.92 * *$ & .98 & $10.67 * * *$ \\
\hline$R^{2}$ & .017 & .079 & .000 & .189 \\
\hline$\Delta R^{2}$ & - & $.05^{* *}$ & - & $.20 * * *$ \\
\hline
\end{tabular}

$* p<.05 ; * * p<.01 ; * * * p<.001$

specific learning goals. This is consistent with the description of lessons in which teachers make use of traditional and transmissive educational methods. According to Lefstein (2008), "such lessons are relatively predictable, in terms of the content covered, likely pupil responses, and the ways in which the teacher is expected to cope with them" (p. 707).

The findings from both sets of hierarchical regression analyses confirmed that interactive practices predict burnout after controlling for school grade and teaching experience. This is a noteworthy result as it shifts the focus from school organisation and classroom characteristics (such as class size) to the role played by the actual and everyday work of teachers in their classrooms. As such, it has important practical implications in the teacher training work and reflective activity.

In particular, we should emphasise that while two findings of the regression analyses were consistent with our hypotheses, a third result was unpredicted. First, as expected, the teachers' adoption of SC Participation practices negatively predicted feelings of emotional exhaustion (set 1 of the regression) and low personal accomplishment (set 2 of the regression). As discussed above, SC Participation practices are highly valued in terms of educational quality and teaching effectiveness (Alexander 2008; Candela 2005; Krummheuer 2011; Mameli and Molinari 2014). Our findings go further in that they also show that the teachers' perception to promote participation and equality led to feelings of professional realisation and prevented from burnout. Despite these associations were reasonable to be assumed, this is an interesting result because, as far as we know, no research so far has moved beyond the analysis of personal and environmental variables, for investigating the role played by everyday teaching interactive practices on professional stress and exhaustion.

A second finding showed that as hypothesised, the perception of adopting TC practices positively predicted feelings of emotional exhaustion (set 1 of the regression). This indicates that teachers who struggle to control the interaction with their students are more liable to experience of frustration in their daily life. We should note that the adoption of TC practices, which limit and constrain student participation, contrasts with the guidelines of effective teaching that are currently promoted in the international debate on the psychology of education (Kovalainen and Kumpulainen 2007; Krummheuer 2011; Niemi et al. 2015; Sfard 2008). It is reasonable, therefore, to conclude that the lesser teachers perceive they are able to accomplish 
the most valorised and virtuous practices, the higher their level of burnout is. Moreover, as pointed out by several authors (Aguiar et al. 2010; Candela 1998; Lefstein and Snell 2013; Mameli and Molinari 2014), it should not be taken for granted that the energy teachers allocate in controlling the discourse trajectories and interactions will be 'rewarded' by an orderly classroom composed of well-behaving students. On the contrary, there is consensus that the way in which classroom interaction unfolds is never "within the solitary control of the teacher" (Aguiar et al. 2010, p. 190) and also that "the teacher will not be able to teach if students refuse to participate" (Candela 1998, p. 191). In these terms, the effort to control interaction, far from being effective in keeping order and limiting misbehaviour, may actually lead to difficulties in classroom management, which may in turn facilitate the burnout onset (Hastings and Bham 2003; Jennings and Greenberg 2009). In addition, students - especially those with learning difficulties or behavioural problems - may feel excluded and frustrated if their needs are confined within rigid boundaries, and eventually manifest boredom, unruliness and noisiness (Geving 2007).

Unexpectedly, a positive though weak predictive association emerged between SC Flexibility and low personal accomplishment (set 2 of the regression). We interpret this finding by advancing that flexibility in classroom conduction, conceptualised as the teachers' capacity to adapt to the emerging educational needs, might go along with a sense of losing control over the activity (Lefstein 2008) that eventually leads to management difficulties. Although most teachers recognise the limits of a trans-missive educational approach and the importance of being ready to grasp learning opportunities as they arise, our results also suggest that the adoption of flexible practices may imply for teachers a relational burden that make them preferring to constrain within the safer pre-set plans and conditions. Further research is certainly needed to achieve a better understanding of these complex dynamics.

\section{Limitations and conclusion}

We certainly need to acknowledge some limitations to this study, which are mainly of a methodological nature. First, the results are limited with respect to the size of the sample and the scale used for measuring teaching interactive practices, which was purpose-built for this study. Replication studies on larger samples are needed to further examine the external reliability of the scale. Moreover, confirmatory factor analyses will have to be carried out to verify its construct validity. Finally, the use of self-report and purpose-built questionnaires raises the question as to how far the statements about teaching practices are represented. Notwithstanding these limita-tions, the internal consistencies we obtained were acceptable for a purpose-built scale. Moreover, we could verify the strength of associations between practices and burnout that were independent by school grade and teaching experience, and as such, emphasise the importance of improving classroom lessons to reduce the costs of teacher burnout.

In conclusion, the results reported here have both theoretical and practical implications for teacher work and training. Developing awareness about the risks to adopt controlling TC practices should to a great extent be a main purpose of teacher education. Even most importantly, our findings encourage teachers and teacher trainers to consider the importance of facilitating and fostering student participation, for the sake and well-being of both the students and the teachers themselves. Sustaining and acknowledging their voices and opinions in school is a worthy goal for increasing student engagement. For this reason, it should be settled as the core business of education. 


\section{References}

Aguayo, R., Pecino, C. V., de la Fuente Solana, E. I., \& Fernández, L. M. L. (2011). A meta-analytic reliability generalization study of the Maslach Burnout Inventory. International Journal of Clinical and Health Psychology, 11(2), 343-361.

Aguiar, O. G., Mortimer, E. F., \& Scott, P. (2010). Learning from and responding to students' questions: the authoritative and dialogic tension. Journal of Research in Science Teaching, 47(2), 174-193.

Alexander, R. J. (2001). Culture and pedagogy: international comparisons in primary education. Oxford: Blackwell.

Alexander, R. J. (2006). Towards dialogic teaching: rethinking classroom talk. NewYork: Dialogos.

Alexander, R. J. (2008). Essays on pedagogy. London: Routledge.

Allen, J., Gregory, A., i Mikami, A., Lun, J., Hamre, B., \& Pianta, R. (2013). Research into practice. School Psychology Review, 42(1), 76-98.

Aloe, A. M., Shisler, S. M., Norris, B. D., Nickerson, A. B., \& Rinker, T. W. (2014). A multivariate meta-analysis of student misbehavior and teacher burnout. Educational Research Review, 12, 30- 44.

Aydogan, I., Dogan, A. A., \& Bauram, N. (2009). Burnout among Turkish high school teachers working in Turkey and abroad: a comparative study. Electronic Journal of Research in Education Psychology, 7, 1249-2095.

Baeten, M., Kyndt, E., Struyven, K., \& Dochy, F. (2010). Using student-centred learning environments to stimulate deep approaches to learning: factors encouraging or discouraging their effectiveness. Educational Research Review, 5(3), 243-260.

Ball, D. L., \& Forzani, F. M. (2009). The work of teaching and the challenge for teacher education. Journal of Teacher Education, 60(5), 497-511.

Ballet, K., \& Kelchtermans, G. (2009). Struggling with workload: primary teachers' experience of intensification. Teaching and Teacher Education, 25(8), 1150-1157.

Bataineh, O. (2009). Sources of social support among special education teachers in Jordan and their relationship to burnout. International Education, 39, 65-78.

Betoret, F. D., \& Artiga, A. G. (2010). Barriers perceived by teachers at work, coping strategies, self-efficacy and burnout. The Spanish Journal of Psychology, 13(02), 637-654.

Boles, J. S., Dean, D. H., Ricks, J. M., Short, J. C., \& Guangping, W. (2000). The dimensionality of the Maslach Burnout Inventory across small business owners and educators. Journal of Vocational Behaviour, 56, $12-34$.

Brocato, K. (2009). Studio based learning: proposing, critiquing, iterating our way to person-centeredness for better classroom management. Theory into Practice, 48(2), 138-146.

Burns, C., \& Myhill, D. (2004). Interactive or inactive? A consideration of the nature of interaction in whole class teaching. Cambridge Journal of Education, 34, 35-49.

Buty, C., \& Mortimer, E. F. (2008). Dialogic/authoritative discourse and modelling in a high school teaching sequence on optics. International Journal of Science Education, 30(12), 1635-1660.

Candela, A. (1998). Students' power in classroom discourse. Linguistics and Education, 10(2), 139-163.

Candela, A. (2005). Students' participation as co-authoring of school institutional practices. Culture \& Psychology, 11, 321-337.

Cano-Garcia, F. J., Padilla-Munoz, E. M., \& Carrasco-Ortiz, M. A. (2005). Personality and contextual variables in teacher burnout. Personality and Individual Differences, 38, 929-940.

Chan, D. W. (2006). Emotional intelligence and components of burnout among Chinese secondary school teachers in Hong Kong. Teaching \& Teacher Education: An International Journal of Research and Studies, 22(8), 1042-1054.

Chaplain, R. P. (2008). Stress and psychological distress among trainee secondary teachers in England. Educational Psychology, 28, 195-209.

Eley, M. G. (2006). Teachers' conceptions of teaching, and the making of specific decisions in planning to teach. Higher Education, 51(2), 191-214.

Ferguson, D. L. (2008). International trends in inclusive education: the continuing challenge to teach each one and everyone. European Journal of Special Needs Education, 23(2), 109-120.

Freiberg, H. J., \& Lamb, S. M. (2009). Dimensions of person-centered classroom management. Theory into Practice, 48(2), 99-105.

Garrett, T. (2008). Student-centered and teacher-centered classroom management: a case study of three elementary teachers. The Journal of Classroom Interaction, 34-47.

Gavish, B., \& Friedman, I. A. (2010). Novice teachers' experience of teaching: a dynamic aspect of burnout. Social Psychology of Education, 13, 141-167.

Geving, A. M. (2007). Identifying the types of student and teacher behaviours associated with teacher stress. Teaching and Teacher Education, 23, 624-640.

Gold, Y., \& Roth, R. A. (2013). Teachers managing stress \& preventing burnout. London: Routledge. 
Grayson, J. L., \& Alvarez, H. K. (2008). School climate factors relating to teacher burnout: a mediator model. Teaching and Teacher Education: An International Journal of Research and Studies, 24(5), 1349-1363.

Greenglass, E. R., \& Burke, R. J. (2003). Teacher stress. In M. F. Dollard, A. H. Winefield, \& H. R. Winefield (Eds.), Occupational stress in the service professions (pp. 213-236). New York: Taylor and Francis.

Guglielmi, D., Simbula, S., \& Panari, C. (2012). The determinants of teachers' well-being: the mediating role of mental fatigue. European Journal of Mental Health, 2, 204-220.

Hastings, R. P., \& Bham, M. S. (2003). The relationship between student behaviour patterns and teacher burnout. School Psychology International, 24(1), 115-127.

Higham, R. J. E., Brindley, S., \& Van de Pol, J. (2014). Shifting the primary focus: assessing the case for dialogic education in secondary classrooms. Language and Education, 28(1), 86-99.

Hughes, J. N., Luo, W., Kwok, O., \& Loyd, L. (2008). Teacher-student support, effortful engagement, and achievement: a three-year longitudinal study. Journal of Educational Psychology, 100, 1-14.

Italian Ministry of Education (2013). Gli alunni stranieri nel sistema scolastico italiano. Resource document. http://www.istruzione.it/allegati/Notiziario_Stranieri_12_13.pdf. Accessed 09 October 2015.

Jennings, P. A., \& Greenberg, M. T. (2009). The prosocial classroom: teacher social and emotional competence in relation to student and classroom outcomes. Review of Educational Research, 79(1), 491-525.

Kane, R., Sandetto, S., \& Heath, C. (2002). Telling half the story: a critical review of research on the teaching beliefs and practices of university academics. Review of Educational Research, 72, 177-228.

Kember, D. (1998). Teaching beliefs and their impact on students' approaches to learning. In B. Dart \& G. Boulton-Lewis (Eds.), Teaching and learning in higher education (pp. 1-25). Camberwell: Australian Council for Educational Research.

Khan, F., Yusoff, R. M., \& Khan, A. (2014). Job demands, burnout and resources in teaching a conceptual review. World Applied Sciences Journal, 30(1), 20-28.

Klassen, R. M., \& Chiu, M. M. (2010). Effects on teachers' self-efficacy and job satisfaction: teacher gender, years of experience, and job stress. Journal of Educational Psychology, 102(3), 741.

Kloser, M. (2014). Identifying a core set of science teaching practices: a delphi expert panel approach. Journal of Research in Science Teaching, 51(9), 1185-1217.

Kokkinos, C. M. (2006). Factor structure and psychometric properties of the Maslach Burnout Inventory-Educators Survey among elementary and secondary school teachers in Cyprus. Stress and Health, 22(1), 25-33.

Kokkinos, C. M. (2007). Job stressors, personality and burnout in primary school teachers. British Journal of Educational Psychology, 77(1), 229-243.

Kovalainen, M., \& Kumpulainen, K. (2007). The social construction of participation in an elementary classroom community. International Journal of Educational Research, 46(3), 141-158.

Krummheuer, G. (2011). Representation of the notion "learning-as-participation" in everyday situations of mathematics classes. Zdm, 43(1), 81-90.

Lee, R. T., \& Ashforth, B. E. (1996). A meta-analytic examination of the correlates of the three dimensions of job burnout. Journal of Applied Psychology, 81, 123-133.

Lefstein, A. (2008). Changing classroom practice through the English National Literacy Strategy: a microinteractional perspective. American Educational Research Journal, 45(3), 701-737.

Lefstein, A., \& Snell, J. (2011). Classroom discourse: the promise and complexity of dialogic practice. Applied Linguistics and Primary School Teaching, 165-185.

Lefstein, A., \& Snell, J. (2013). Better than best practice: developing dialogic pedagogy. London: Routledge.

Lin, A. M. Y. (2007). "What's the use of "triadic dialogue"? Activity theory, conversation analysis and analysis of pedagogical practices. Pedagogies, 2, 77-94.

Lipponen, L., \& Kumpulainen, K. (2011). Acting as accountable authors: creating interactional spaces for agency work in teacher education. Teaching and Teacher Education, 27(5), 812-819.

Lyle, S. (2008). Dialogic teaching: discussing theoretical contexts and reviewing evidence from classroom practice. Language and Education, 22(3), 222-240.

Mameli, C., \& Molinari, L. (2014). Seeking educational quality in the unfolding of classroom discourse: a focus on microtransitions. Language \& Education, 28(2), 103-119.

Mameli, C., Mazzoni, E., \& Molinari, L. (2015). Patterns of discursive interactions in primary schools: an application of social network analysis. Research Papers in Education, 30(5), 546-566.

Mascolo, M. F. (2009). Beyond student-centered and teacher-centered pedagogy: teaching and learning as guided participation. Pedagogy and the Human Sciences, 1(1), 3-27.

Maslach, C., \& Jackson, S. E. (1981). Maslach burnout inventory (1st ed.). Palo Alto: Consulting Psychologists Press.

Maslach, C., Jackson, S. E., \& Leiter, M. P. (1996a). Maslach burnout inventory manual (3rd ed.). Palo Alto: Consulting Psychologist Press.

Maslach, C., Jackson, S. E., \& Schwab, R. L. (1996b). Maslach Burnout Inventory-Educators Survey (MBI-ES). In C. Maslach, S. E. Jackson, \& M. P. Leiter (Eds.), MBI manual (3rd ed.). Palo Alto: Consulting Psychologists Press. 
Maslach, C., Schaufeli, W. B., \& Leiter, M. P. (2001). Job burnout. Annual Review of Psychology, 52, 397-422. McCormick, J., \& Barnett, K. (2011). Teachers' attributions for stress and their relationships with burnout. International Journal of Educational Management, 25(3), 278-293.

Mercer, N. (2008). Talk and the development of reasoning and understanding. Human Development, 51(1), 90-100.

Mercer, N., \& Howe, C. (2012). Explaining the dialogic processes of teaching and learning: the value and potential of sociocultural theory. Learning, Culture and Social Interaction, 1(1), 12-21.

Mercer, N., \& Littleton, K. (2007). Dialogue and the development of children's thinking: a sociocultural approach. New York: Routledge.

Molinari, L., \& Mameli, C. (2013). Process quality of classroom discourse: pupil participation and learning opportunities. International Journal of Educational Research, 62, 249-258.

Montgomery, C., \& Rupp, A. A. (2005). Meta-analysis for exploring the diverse causes and effects of stress in teachers. Canadian Journal of Education, 28, 458-486.

Mortimer, E. F., \& Scott, P. H. (2003). Meaning making in secondary science classrooms. Maidenhead: Open University Press.

Nassaji, H., \& Wells, G. (2000). What's the use of triadic dialogue? An investigation of teacher student interaction. Applied Linguistics, 21(3), 376-406.

Niemi, R., Kumpulainen, K., \& Lipponen, L. (2015). Pupils as active participants: diamond ranking as a tool to investigate pupils' experiences of classroom practices. European Educational Research Journal, 14(2), 138150 .

Nystrand, M. (1997). Opening dialogue: understanding the dynamics of language and learning in the English classroom. New York: Teachers College Press.

Pedditzi, M. L., \& Nonnis, M. (2014). Fonti psico-sociali di stress e burnout a scuola: Una ricerca su un campione di docenti italiani. La Medicina del Lavoro, 105(1), 48-62.

Quattrin, R., Ciano, R., Saveri, E., Balestrieri, M., Biasin, E., Calligaris, L., \& Brusaferro, S. (2009). Burnout in teachers: an Italian survey. Annali di Igiene: Medicina Preventiva e di Comunita, 22(4), 311-318.

Schaufeli, W. B., Leiter, M. P., \& Maslach, C. (2009). Burnout: 35 years of research and practice. Career Development International, 14(3), 204-220.

Scott, P. H., Mortimer, E. F., \& Aguiar, O. G. (2006). The tension between authoritative and dialogic discourse: a fundamental characteristic of meaning making interactions in high school science lessons. Science Education, 90, 605-631.

Sfard, A. (2008). Thinking as communicating. Human development, the growth of discourses, and mathematizing. Cambridge: Cambridge University Press.

Simbula, S., \& Guglielmi, D. (2010). Depersonalization or cynicism, efficacy or inefficacy: what are the dimensions of teacher burnout? European Journal of Psychology of Education, 25(3), 301-314.

Sirigatti, S., \& Stefanile, C. (1992). Aspetti e problemi dell'adattamento italiano del MBI. Bollettino di Psicologia Applicata, 202-203, 3-12.

Skaalvik, E. M., \& Skaalvik, S. (2009). Does school context matter? Relations with teacher burnout and job satisfaction. Teaching and Teacher Education, 25(3), 518-524.

Skidmore, D. (2006). Pedagogy and dialogue. Cambridge Journal of Education, 36(4), 503-514.

Skidmore, D., \& Murakami, K. (2010). How prosody marks shifts in footing in classroom discourse. International Journal of Educational Research, 49, 69-77.

Spillane, J. P. (2012). Data in practice: conceptualizing the data-based decision-making phenomena. American Journal of Education, 118(2), 113-141.

Tatar, M., \& Horenczyk, G. (2003). Diversity-related burnout among teachers. Teaching and Teacher Education, 19(4), 397-408.

Taylor, D. L., \& Tashakkori, A. (1995). Decision participation and school climate as predictors of job satisfaction and teachers' sense of efficacy. Journal of Experimental Education, 63, 217-231.

Travers, C. J., \& Cooper, C. L. (1996). Teachers under pressure: stress in the teaching profession. London: Routledge.

Tsigilis, N., Zournatzi, E., \& Koustelios, A. (2011). Burnout among physical education teachers in primary and secondary schools. International Journal of Humanities and Social Science, 7(1), 53-58.

Tsouloupas, C. N., Carson, R. L., Matthews, R., Grawitch, M. J., \& Barber, L. K. (2010). Exploring the association between teachers' perceived student misbehaviour and emotional exhaustion: the importance of teacher efficacy beliefs and emotion regulation. Educational Psychology, 30(2), 173-189.

Veldman, I., van Tartwijk, J., Brekelmans, M., \& Wubbels, T. (2013). Job satisfaction and teacherstudent relationships across the teaching career: four case studies. Teaching and Teacher Education, 32, 55-65.

Vercambre, M. N., Brosselin, P., Gilbert, F., Nerrière, E., \& Kovess-Masféty, V. (2009). Individual and contextual covariates of burnout: a cross-sectional nationwide study of French teachers. BMC Public Health, 9(1), 333.

Wegerif, R. (2008). Dialogic or dialectic? The significance of ontological assumptions in research on educational dialogue. British Educational Research Journal, 34(3), 347-361. 
Wegerif, R., Mercer, N., \& Dawes, L. (1999). From social interaction to individual reasoning: an empirical investigation of a possible socio-cultural model of cognitive development. Learning and Instruction, 9(6), 493-516.

Wells, G., \& Arauz, R. M. (2006). Dialogue in the classroom. The Journal of the Learning Sciences, 15, 379428.

Worley, J. A., Vassar, M., Wheeler, D. L., \& Barnes, L. L. B. (2008). Factor structure of scores from the Maslach Burnout Inventory: a review and meta-analysis of 45 exploratory and confirmatory factor- analytic studies. Educational and Psychological Measurement, 68, 797-823.

Xin, M., \& MacMillan, R. B. (1999). Influence of workplace conditions on teachers' job satisfaction. Journal of Educational Research, 93, 39-47.

Yüksel, D. (2009). A Bakhtinian understanding of social constructivism in language teaching. Journal of Language and Linguistic Studies, 5(1), 1-19.

Zurlo, M. C., Pes, D., \& Cooper, C. L. (2007). Stress in teaching: a study of occupational stress and its determinants among Italian schoolteachers. Stress and Health, 23(4), 231-241.

Consuelo Mameli University of Bologna, Department of Education, Via Filippo Re 6, 40126 Bologna, Italy. E-mail: consuelo.mameli@unibo.it

Current themes of research:

Teacher-student interactions. Classroom discourse. Educational quality. Teacher burnout.

Most relevant publications in the field of the Psychology of Education:

Mameli, C., Mazzoni, E., \& Molinari, L. (2015). Patterns of discursive interactions in primary schools: An application of Social Network Analysis. Research Papers in Education, 30(5), 546-566.

Mameli, C., \& Molinari, L. (2014). Seeking educational quality in the unfolding of classroom discourse: A focus on microtransitions. Language \& Education, 28 (2), 103-119.

Mameli, C., \& Molinari, L. (2013). Interactive micro-processes in classroom discourse: Turning Points and emergent meanings. Research Papers in Education, 28(2), 196-211.

Molinari, L., \& Mameli, C. (2013). Process quality of classroom discourse: Pupil participation and learning opportunities. International Journal of Educational Research, 62, 249 - 258.

Molinari, L., Mameli, C., \& Gnisci, A. (2013). A sequential analysis of classroom discourse in Italian primary schools. The many faces of the IRF pattern'. British Journal of Educational Psychology, 83(3), 414-430.

Luisa Molinari University of Parma, Department of Literature Arts History and Society, Borgo Carissimi 10, 40125 Parma, Italy. E-mail: luisa.molinari@unipr.it

Current themes of research:

Classroom discourse and social interaction; rights and responsibilities in education; process of change and microtransitions in families with adolescents; classroom justice.

Most relevant publications in the field of the Psychology of Education:

Mameli, C., Mazzoni, E., \& Molinari, L. (2015). Patterns of discursive interactions in primary schools: An application of Social Network Analysis. Research Papers in Education, 30(5), 546-566.

Passini, S., Molinari, L., Speltini, G. (2015). A validation of the questionnaire on teacher interaction in Italian secondary school students: Effect of positive relations on motivation and academic achievement. Social Psychology of Education, 18, 547-559.

Molinari, L., Mameli, C., \& Gnisci, A. (2013). A sequential analysis of classroom discourse in Italian primary schools. The many faces of the IRF pattern'. British Journal of Educational Psychology, 83(3), 414-430. 
Molinari, L., Speltini, G., \& Passini, S. (2013). Do perceptions of being treated fairly increase students' outcomes? Teacher-student interactions and classroom justice in Italian adolescents. Educational Research and Evaluation, 19(1), 58-76.

Corsaro, W.A., Molinari, L. (2008). Policy and practice in Italian children's transition from preschool to elementary school. Research in Comparative and International Education, 3, 3, 250-265. 